\title{
ГОРИЗОНТЫ ПРИКЛАДНОЙ МИНЕРАЛОГИИ
}

\author{
Институт геологии им. академика Н. П. Юикина Коми НЦ УрО РАН, \\ 167982, Сыктывккар, ул. Первомайская, 54; \\ e-mail: askhabov@geo.komisc.ru; kotova@geo.komisc.ru
}

\begin{abstract}
Статья посвящена итогам 14-го Международного конгресса по прикладной минералогии (ICAM2019), который прошел в Белгородском государственном технологическом университете имени В. Г. Шухова с 23 по 27 сентября, впервые в России. Конгресс стал важной вехой в истории Комиссии по прикладной минералогии Международной минералогической ассоциации (IMA-CAM), определил вектор развития приоритетных научных направлений, эффективные связи науки и бизнеса, лежащие в основе инновационной экономики регионов мира, закрепил позиции России как одной из ведущих стран в области прикладной минералогии.

Ключевые слова: горные породы, минералы, геометаллургия, процессы переработки, биоминералогия, функциональные материалы, экологическая минералогия, аналитические методы, минеральные поверхности, наночастицы.
\end{abstract}

\section{A. M. ASKHABOV, O. B. KOTOVA. HORIZONS OF APPLIED MINERALOGY}

Institute of Geology, Komi Science Centre, Ural Branch RAS, Syktyvkar, Russia

The article is devoted to the results of the 14th International Congress for Applied Mineralogy (ICAM2019) hosted in the V. G. Shukhov Belgorod State Technological University at September 23-27, 2019, Belgorod. The Congress became an important milestone in the history of the Commission for Applied Mineralogy of the International Mineralogical Association (IMA-CAM), determined a vector for the development of priority scientific areas, effective links between science and business in the base of the innovative economies of the world's regions, consolidated position of Russia as one of the leading countries in the field of applied mineralogy.

Keywords: rocks, minerals, geometallurgy, mineral processing, biomineralogy, smart materials, environmental mineralogy, analytical methods, mineral surfaces, nanoparticles.

Прикладная минералогия традиционно развивается на основе взаимного проникновения минералогии и смежных дисциплин, быстрого развития аналитических методов и эксперимента, а также практического применения в современной индустрии, аграрном производстве, медицине и т. д. В результате объединения достижений минералогии с другими дисциплинами (переработка полезных ископаемых, физика, химия, биология, вычислительное моделирование, металлургия, материаловедение, окружающая среда) сформировались многие активные междисциплинарные и прикладные отрасли минералогии, такие как наноминералогия, биоминералогия, технология и дизайн материалов на минеральной основе. Таким образом, прикладная минералогия является важной инновационной составляющей при переходе от минералогии к комплексному использованию полезных ископаемых.

Международные конгрессы по прикладной минералогии проводятся Комиссией по прикладной минералогии в рамках Международной минералогической ассоциации (IMA-CAM) для координации специалистов, проводящих исследования в этой области. Комиссия была создана в 1979 г. после образования Международного совета по прикладной минералогии (ICAM). В 1993 г. в г. Перт (Австралия) было решено, что заседания ICAM будут проходить по четырехлетнему графику между организациями Международных конгрес- 
сов Международной минералогической ассоциации (IMA). Позднее, в 2011 г. в г. Тронхейм (Норвегия) было принято решение о проведении конгрессов каждые два года.

По инициативе IMA-CAM и Комиссии по прикладной минералогии при Международной минералогической ассоциации на базе Белгородского государственного технологического университета имени В. Г. Шухова (БГТУ им. В. Г. Шухова) с 23 по 27 сентября прошел 14-й Международный конгресс по прикладной минералогии $\left(14^{\text {th }}\right.$ International Congress for Applied Mineralogy (ICAM 2019) (www.geo.komisc.ru/icam2019), впервые в России.

Организаторами конгресса выступили: Международная минералогическая ассоциация (IMA); Российское минералогическое общество (PМO); Министерство науки и высшего образования Российской Федерации; Российская академия наук (РАН); Правительство Белгородской области; Российская академия архитектуры и строительных наук (РАACH); Белгородский государственный технологический университет имени В. Г. Шухова (БГТУ им. В. Г. Шухова); Институт геологии имени академика Н. П. Юшкина ФИЦ Коми НЦ УрО РАН (ИГ ФИЦ Коми НЦ УрО РАН); Научно-производственная корпорация «Механобр-техника».

В состав Национального организационного комитета вошли: от Белгородской области Е. С. Савченко - губернатор Белгородской области, чл.-корр. РАН; С. Н. Глаголев - ректор БГТУ им. В. Г. Шухова, профессор; В. В. Строкова - профессор РАН, член Ученого совета РМО. От Российской академии наук академики РАН: Д. В. Рундквист, Д. Ю. Пущаровский, А. О. Глико; член-корреспондент РАН В. В. Масленников; от ОНЗ РАН Н. А. Зайцева; от Комиссии по технологической минералогии РМО и ИГ ФИЦ Коми НЦ УрО РАН И. Н. Бурцев и Н. Н. Тимонина.

Национальный программный комитет возглавил академик РАН Л. А. Вайсберг. В Комитет вошли представители ведущих научных организаций РАН, отраслевых организаций, ВУЗов и производственных объединений академики РАН: А. М. Асхабов, Н. С. Бортников, Н. В. Соболев, В. А. Чантурия; члены-корреспонденты РАН: С. В. Кривовичев, Ю. Б. Марин; доктора наук: Т. Н. Матвеева, О. Б. Котова, Е. Г. Ожогина, О. В. Франк-Каменецкая, В. В. Щипцов.

В состав Международного комитета вошли: от Совета ICAМ Саверио Фиоре (Saverio Fiore), президент Совета, Италия; Ольга Котова, вице-призедент Совета, Россия; генеральный секретарь Совета, Дитер Раммлмайр (Dieter Rammlmair), Германия; от IMA-CAM Мартин Брукманс (Maarten A. T. M. Broekmans), Норвегия, председатель; Ян Элсен (Jan Elsen), секретарь, Бельгия.

Генеральным спонсором конгресса выступила ООО «Управляющая компания Металлоинвест».

Информационную поддержку в организации Конгресса оказали журналы: «Обогащение руд», «Разведка и охрана недр», «Строительные материалы», «Вестник Белгородского государственного технологического университета им. В. Г. Шухова», «Руды и металлы», «Вестник Института геологии Коми НЦ УрО РАН», «Вестник Отделения наук о Земле РАН».

Целевой аудиторией Конгресса стали ученые из Европы, Азии, Америки, Австралии и Африки, в течение пяти дней представляющие новейшие достижения и разработки в исследовании и применении природных богатств планеты. Для участия в конференции было заявлено 122 доклада 340 авторов.

Церемония открытия Конгресса состоялась 23 сентября в Шуховском конгресс-зале БГТУ. С приветственными словами выступили представите- 


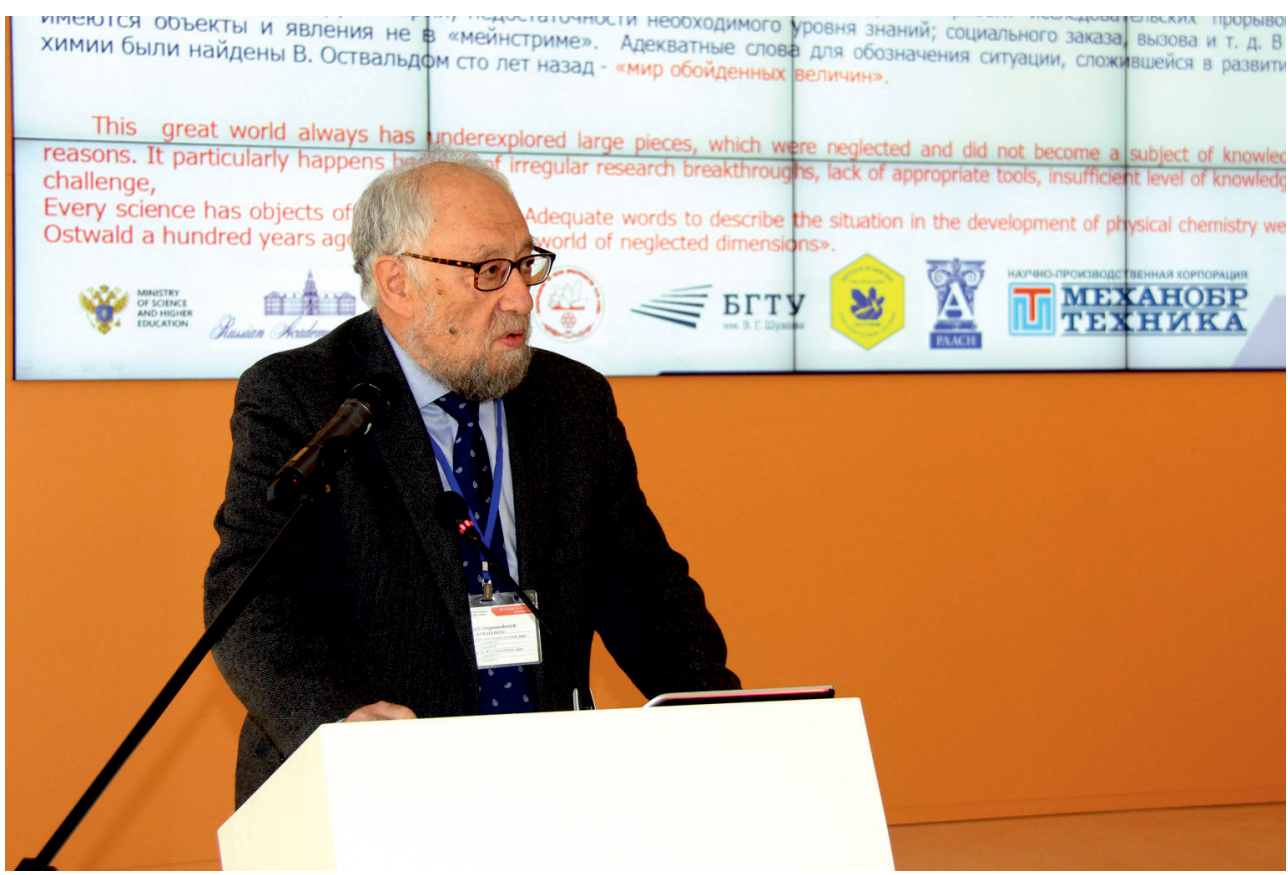

Академик Асхаб Асхабов. Пленарное заседание.

Academician Askhab Akshabov. Plenary meeting.

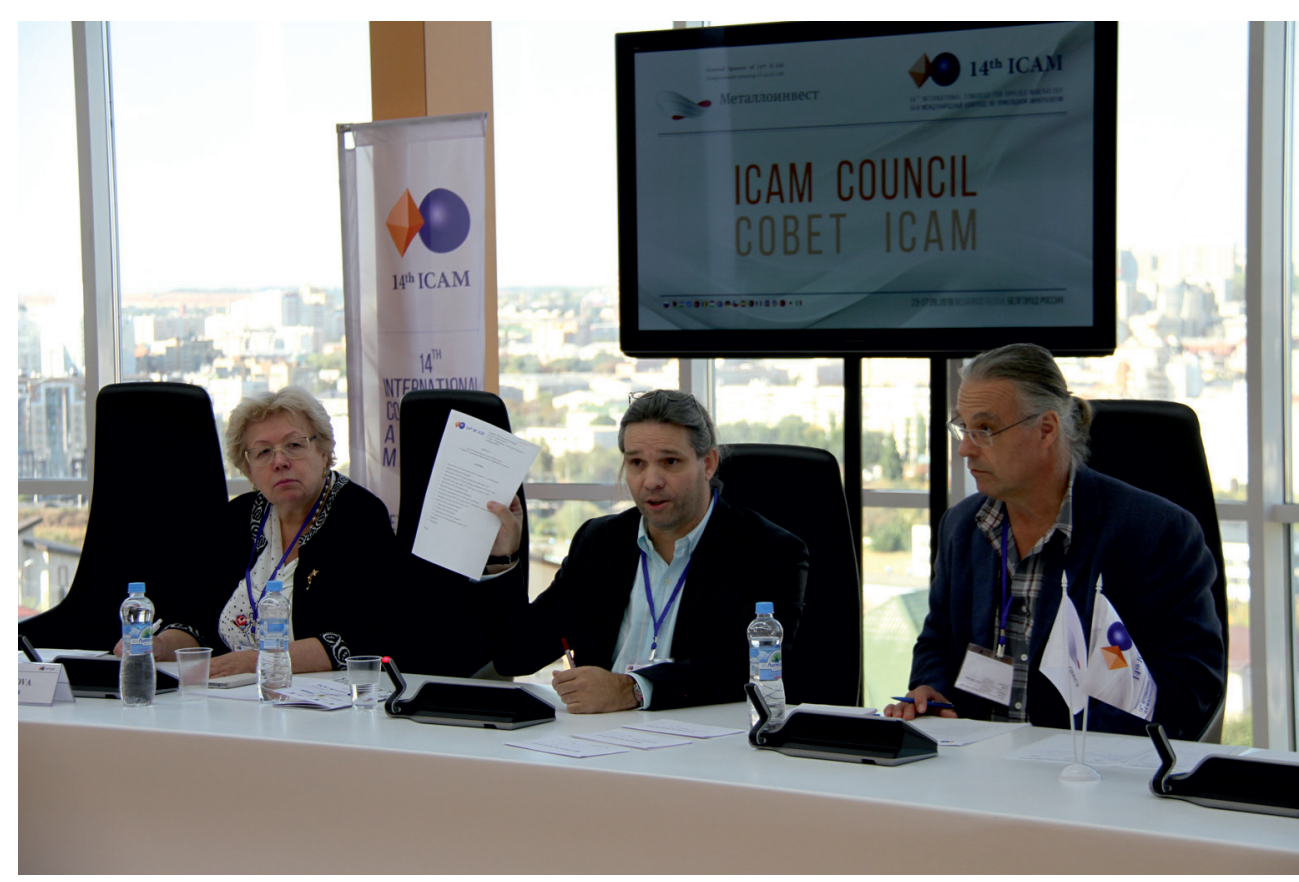

БГТУ им. В. Г. Шухова. Шуховский зал. Заседание Совета. Ольга Котова, Россия; Мартин Брукманс, Норвегия; Дитер Раммлмайр, Германия.

BSTU named after V. G. Shukhov. V. G. Shukhov congress hall. ICAM Council Meeting. Olga Kotova, Russia; Maarten A. T. M. Broekmans, Norway; Dieter Rammlmair, Germany. 
ли Белгородской области, БГТУ, Международной минералогической ассоциации, Российской академии наук и Российского минералогического общества.

Основные научные направления, которые охватил Конгресс, коснулись современных методов исследования горных пород и минералов, полезных ископаемых, геометаллургии и процессов переработки, биоминералогии, функциональных материалов, углеводородного сырья, экологии (Прикладная.., 2018), в рамках которых работали 9 секций, сделано 16 пленарных, 70 устных и 36 стендовых докладов (Котова, 2019).

Докладчики Пленарной сессии отразили наиболее значимые проблемы прикладной минералогии. Академик Асхаб Асхабов (ИГ ФИЦ Коми НЦ УрО РАН, Сыктывкар) в своем докладе, посвященном результатам и перспективам минералогического вторжения в наномир, среди прочего отметил появление протоминерального мира в повестке дня минералогической науки и связал перспективы развития минералогической науки, в том числе прикладной минералогии, с программой первоочередных экспериментов по изучению нанобъектов (в диапазоне от отдельных атомов и молекул до первых «наноиндивидов» минерального вещества) с привлечением Европейского лазера на свободных электронах (Askhabov, 2019).

Дальнейшее развитие взаимосвязанных проблем рационального использования природных ресурсов ученые возлагают на качественно новый уровень исследований минерального и вещественного состава многокомпонентных руд, предлагая свои методы и подходы, например академик Валентин Чантурия и доктор технических наук Тамара Матвеева (Институт проблем комплексного освоения недр РАН, Москва) с позиции комплексной и глубокой переработки (Chanturiya, Matveeva, 2019) или с позиции инноваций в инжинеринге на примере молибдо-щеелитовых руд (Леонид Вайсберг, Иван Устинов, НПО «Механобр-Техника», Санкт-Петербург и Олег Кононов, Московский государственный университет, Москва) (Vaisberg et al., 2019). Объединив свой научный потенциал в области технологической минералогии Ольга Котова (ИГ ФИЦ Коми НЦ УрО РАН, Сыктывкар) и Елена Ожогина (ВИМС, Москва) продемонстрировали алгоритм прогноза вовлечения во вторичную переработку отходов горнодобывающих и перерабатывающих производств на примере Ni- и Al-сырья (Kotova, Ozhogina, 2019).

Китайские коллеги (профессора Факин Донг, Кунвей Дай и Шионг Сан, Юго-Западный университет науки и техники Китая, Миньянг) сфокусировали внимание на системе микроорганизм-минерал-поллютант и инновациях с целью повышения возможностей в поле контроля гидрогеологических условий ландшафта (на примере травертина основных объектов наследия Цзючжайгоу), загрязнения окружающей среды и технологий экологической реабилитации (Dong et al., 2019; Sun et al., 2019).

Член-корреспондент РАН Валерий Масленников (Институт минералогии УрО РАН) обобщил результаты 15 летней работы совместно с профессором Россом Ларгом (Тасманский университет, Австралия) в области LA-ICP-MS геохимии массивных сульфидных и орогенных месторождений золота (Maslennikov et al., 2019).

Дитер Раммлмайр и другие немецкие коллеги подчеркнули важность геохимии и минералогии хвостов при формировании экономического потенциала страны и стратегии уменьшения воздействия на окружающую среду на примере медного рудника на севере центральной части Чили (Berkh et al., 2019). 
Член-корреспондент РАН Сергей Кривовичев с соавторами предложили муратаит-пирохлор титанатную керамику для иммобилизации радиоактивных отходов сложного состава, что исключает необходимость дальнейшего химического воздействия (Krivovichev et al., 2019).

Фернандо Роча с коллегами из португальского университета г. Авейру предложены методы и подходы улучшения свойств геополимеров на основе отходов (Rocha et al., 2019).

Доклад Натальи Тимониной (ИГ ФИЦ Коми НЦ УрО РАН, Сыктывкар) был посвящен влиянию глинистых минералов песчаных пород-коллекторов триасового возраста арктических районов Тимано-Печорской нефтегазоносной провинции на фильтрационные и емкостные свойства последних, оценке качества коллекторов и покрышек с целью повышения эффективности нефтеотдачи пласта и увеличению объемов добычи углеводородов (Timonina, 2019).

В докладах ученых БГТУ (Lesovik et al., 2019), а также французских коллег (Le Saout et al., 2019) были подняты проблемы прикладной минералогии строительной индустрии.

В докладе Ольги Франк-Каменецкой с соавторами нашли отражение проблемы, связанные с сохранением памятников в городской среде: идентификацией камня, разработкой методов мониторинга состояния камня и стратегии его сохранения (Frank-Kamenetskaya et al., 2019).

В презентации профессора Технического университета Стамбула Эмина Чифчи были представлены образцы дымчатого кварца, синего халцедона, изумруда и других полудрагоценных и драгоценных камней из месторождений Турции, продемонстрированы аналитические возможности их исследования. Ученый считает, что сегодня с увеличением научных знаний и технических возможностей геммология, как направление прикладной минералогии, переживает свой золотой век (Çiftçi, 2019).

Секционные заседания активно работали в течении трех дней Конгресса. Секция Т1 «Геометаллургия, технологическая минералогия и процессы переработки минерального сырья» была самой представительной с акцентом на исследование вещественного состава тонковкрапленных руд цветных и черных металлов и доминирование комбинированных технологий переработки труднообогатимых руд и промышленных отходов. Большой интерес вызвали доклады в области исследования перспективных типов руд, содержащих слоистые и глинистые минералы. Доклады, представленные на секции T2 «Индустриальные минералы, драгоценные камни, руды и добыча полезных ископаемых», продемонстрировали важнейшее значение прикладной минералогии при оценке металлов и промышленных минералов, драгоценных камней в условиях жесткой конкуренции, дефицита сырья и экологических рисков.

Важным результатом Конгресса стала книга объемом почти в 500 страниц - Труды 14-го Международного конгресса по прикладной минералогии (ICAM2019), под редакцией профессора С. Н. Глаголева, ректора Белгородского государственного технологического университета им. В. Г. Шухова, опубликованная в издательстве Шпрингер (https://link.springer.com/book/10.1007/ 978-3-030-22974-0), в серии Springer Proceedings in Earth and Environmental Sciences.

Согласно данным опубликованной книги в работе Конгресса приняли участие более 400 ученых и специалистов в области прикладной минералогии из 21 страны мира (России, Китая, Португалии, Германии, Японии, Турции, 
Узбекистана, Франции, Чили, Казахстана, Австралии, Беларуси, США, Венгрии, Испании, Румынии, Ливана, Кот д’Ивуара, Алжира, Италии, Норвегии) из 46 организаций, из них 29 - представители академических организаций, 44 - высших учебных заведений, 23 - промышленных компаний, научных журналов, в том числе 8 академиков РАН, 4 чл.-корр. РАН, доктора и кандидаты наук, инженеры, предприниматели, аспиранты и магистранты.

Большой интерес участников Конгресса вызвала полевая экскурсия на Лебединский ГОК (г. Губкин) - крупнейшее в России предприятие по добыче и обогащению железной руды и производству высококачественного железорудного сырья.

В последний день Конгресса работала научная Школа «Роль прикладной минералогии в исследовании индустриальных минералов (опыт работы Комиссии по технологической минералогии РМО)». Во время проведения научной Школы профессор Владимир Щипцов - председатель Комиссии по технологической минералогии РМО, заведующий отделом минерального сырья Института геологии КарНЦ РАН - представил развернутый доклад на русском и английском языках об истории технологической минералогии. Ведущий обратил внимание слушателей на предпосылки и причины развития данного научного направления, выделил основные этапы его формирования, рассказал о главных принципах и тенденциях развития технологической минералогии на сегодняшний день.

Дискуссионный клуб с темой «Обработка больших данных в геологоразведке» (Big data handling in exploration) возглавил Дитер Раммлмайр (Dieter Rammlmair, Германия).

На втором и четвертом этажах БГТУ работала выставка ЕХРО/ІСАМ2019 производственного оборудования, исследовательской техники, отраслевого программного обеспечения. Участниками выставки стали: производитель технологического оборудования НПК «Механобр-техника» (Санкт-Петербург), производитель панорамных микроскопов группа компаний «SIAMS» (Екатеринбург), производитель анализаторов размера частиц «Beckman Coulter», США (представительство в Санкт-Петербурге); разработчик программного обеспечения ООО «Современные изыскательские технологии» (Москва); производитель оборудования для определения химического и фазового состава «Термо Техно» (Москва); белгородские строительные предприятия и производители строительных материалов, малые инновационные предприятия университета, в том числе ООО «Композит» - производитель сухих строительных смесей марки «Экоцемент».

В рамках Конгресса состоялось заседание Совета ICAM (ICAM Council), в работе которого приняли участие представители 11 стран. Совет ICAM подвел итоги работы Конгресса (ICAM2019):

- отметил хорошую работу команды Конгресса (Национальный организационный комитет, Национальный программный комитет, Совет ICAM при поддержке от IMA-CAM), что привело к успешной реализации проекта ICAM2019;

— подчеркнул важный результат Конгресса — Труды 14-го Международного конгресса по прикладной минералогии;

- подтвердил решение Совета ICAM, который проходил в 2017 г. в Италии, Кастелланета Марина (ICAM2017), о проведении 15-го Международного конгресса по прикладной минералогии в Португалии, Университет Авейру, в июле 2021 г.; 


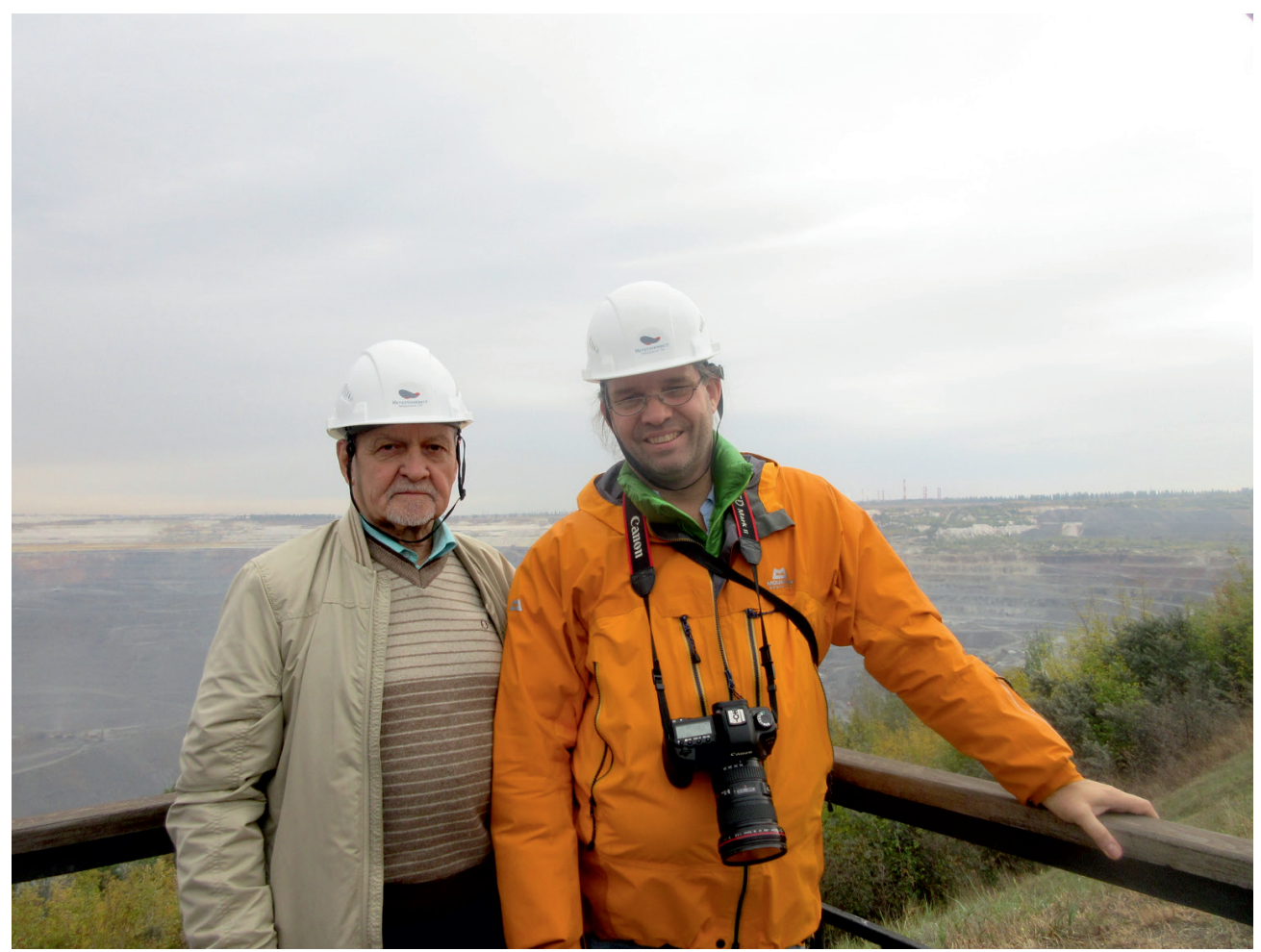

Полевая экскурсия на Лебединский ГОК. Проф. Владимир Щипцов, Россия, и проф. Мартин Брукманс, Норвегия.

Field trip at the Lebedinsky Processing Plant. Prof. Vladimir Shchiptsov, Russia and Prof. Maarten A. T. M. Broekmans, Norway.

- определил новый состав Совета ICAM: президент - Ольга Котова, Россия, вице-президент Фернандо Роче (Fernando Roche), Португалия, генеральный секретарь - Дитер Раммлмайр, Германия; второй секретарь - Дечентри Четти, ЮАР, а также представитель в IMA/CAM от Совета ICAM Мартин Брукманс;

- по итогам конкурса на право проведения 16-го Международного конгресса по прикладной минералогии в 2023 г. был выбран Юго-Западный Университет Науки и Технологии, Ченгду, Китай. Боролись две страны: Чили (Консепсьон, Университет Консепсьона) и Китай (Ченгду, Юго-Западный Университет Науки и Технологии).

В рамках культурной программы участников Конгресса ждал великолепный концерт органной музыки в Белгородской филармонии, экскурсии, связанные с боевыми действиями на Белгородчине в период ВОВ, пешие прогулки по достопримечательностям города в солнечную погоду.

Конгресс, девиз которого - «Прикладная минералогия: будущее рождается сегодня», стал важной вехой в истории Комиссии по прикладной минералогии Международной минералогической ассоциации, определил вектор развития приоритетных научных направлений, эффективные связи науки и бизнеса, лежащие в основе инновационной экономики регионов мира, закрепил позиции России как одной из ведущих стран в области прикладной мине- 


\section{ICAM2019: Proceedings of the Congress}
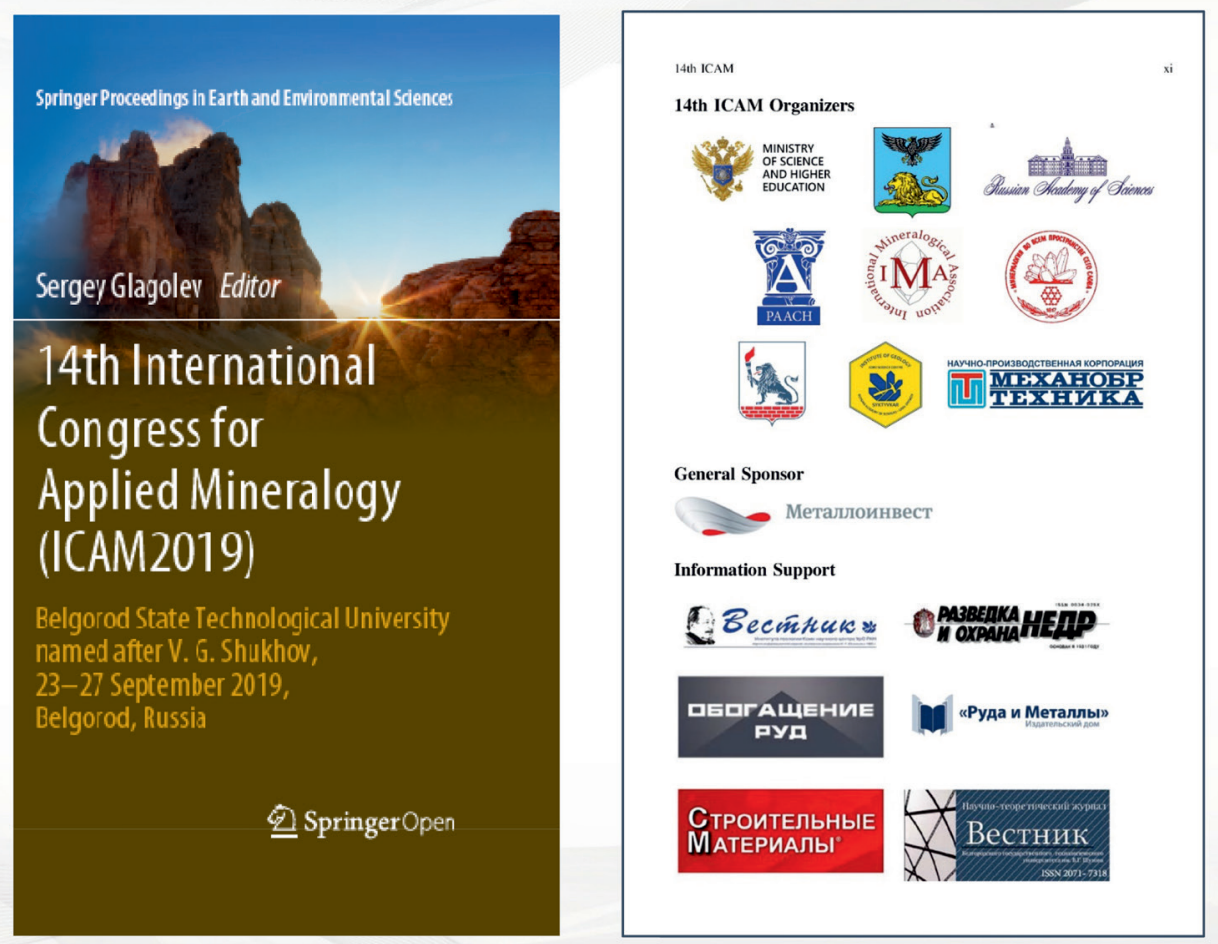

Труды Конгресса; логотипы организаторов и информационной поддержки Конгресса.

Congress Proceedings; logos of organizers and information support of the Congress.

ралогии. Надеемся, что молодые участники Конгресса получили новые знания и новые возможности для активного участия в современных вызовах прикладной минералогии. До встречи в июле 2021 года в Португалии (Университет Авейру) на 15-м Международном конгрессе по прикладной минералогии (ICAM2021)!

\section{Список литературы}

Прикладная минералогия: из Бари в Белгород // Вестник Института геологии Коми НЦ УpO РАН. 2018. № 4. С. 51.

Котова О.Б. Прикладная минералогия: из Белгорода в Авейро // Вестник Института геологии Коми НЦ УрО РАН. 2019. № 9. С. 43-54.

\section{References}

Askhabov A. Mineralogical Breakthrough into Nanoworld: Results and Challenges. 14th International Congress for Applied Mineralogy (ICAM2019). Springer Proceedings in Earth and Environmental Sciences. 2019. P. $33-36$.

Berkh K., Rammlmair D., Drobe M., Meima J. Case Study: Geochemistry and Mineralogy of Copper Mine Tailings in Northern Central-Chile. Ibid. P. 37-40.

Chanturiya V., Matveeva T. Applied Mineralogy for Complex and Profound Mineral Processing. Ibid. P. 69-72. 
Çiftçi E., Selim H., Sendir H. Authentic Semi-precious and Precious Gemstones of Turkey: Special Emphasis on the Ones Preferred for Prayer Beads. Ibid. P. 183-188.

Dong F., Dai Q., Li Q., Wang F., Luo Y. Effect of Earthquake on the Landscape of Jiuzhaigou-Huanglong Travertine and Its Restoration. Ibid. P. 413-414.

Frank-Kamenetskaya O., Vlasov D., Rytikova V., Parfenov V., Manurtdinova V., Zelenskaya M. Monitoring of the State of St. Petersburg Stone Monuments and the Strategy of Their Preservation. Ibid. P. $479-482$.

Krivovichev S., Yudintsev S., Pakhomova A., Stefanovsky S. Murataite-Pyrochlore Ceramics as Complex Matrices for Radioactive Waste Immobilization: Structural and Microstructural Mechanisms of Crystallization. Ibid. P. 447-450.

Kotova O. B. Applied Mineralogy: from Belgorod to Aveiro. Vestnik of the Institute of Geology. 2019. No. 9. P. 43-54.

Kotova O., Ozhogina E. Applied Mineralogy of Mining Industrial Wastes. 14th International Congress for Applied Mineralogy (ICAM2019). Springer Proceedings in Earth and Environmental Sciences. 2019. P. $103-106$.

Lesovik V., Volodchenko A., Glagolev E., Lashina I., Fischer H.-B. Geonics (Geomimetics) as a Theoretical Basis for New Generation Compositing. Ibid. P. 344-347.

Maslennikov V., Maslennikova S., Aupova N., Tseluyko A., Large R., Danyushevsky L., Yatimov U. High-Tech Elements in Minerals of Massive Sulfide Deposits: LA-ICP-MS Data. Ibid. P. 107-110.

Rocha F., Costa C., Hajjaji W., Andrejkovičová S., Moutinho S., Cerqueira A. Properties Improvement of Metakaolin-Zeolite-Diatomite-Red Mud Based Geopolymers. Ibid. P. 381-384.

Sun S., Wang K., Dong F., Ma B., Huo T., Zhao Y., Yu H., Huang Y., Huang J. Structure and Surface Reactivity Mediated Enzymatic Performances of Clay-Based Nanobiocatalyst. Ibid. P. 290-291.

Timonina N. Oil and Gas Reservoirs in the Lower Triassic Deposits in the Arctic Regions of the Timan-Pechora Province. Ibid. P. 223-226.

Vaisberg L., Kononov O., Ustinov I. Process Mineralogy as a Basis of Molybdoscheelite Ore Preparation. Ibid. P. 152-156.

Поступила в редакцию 31 октября 2019 г. 